\title{
Surface Modification and Dielectric Response Investigation of Cellulose Acetate Membrane Treated by ArF Excimer Laser
}

\author{
Ali Pourakbar Saffar ${ }^{1,2 *}$, Babak Jaleh³, Parviz Parvin4, Pikul Wanichapichart ${ }^{5,6}$, \\ Mahdi Farshchi-Tabrizi ${ }^{3,7}$ \\ ${ }^{1}$ Laser Laboratory, Research Center of Informatic Industries, Tehran, Iran \\ ${ }^{2}$ Physics Department and Young Researchers Club \& Elites, Islamic Azad University Central Tehran Branch, \\ Tehran, Iran \\ ${ }^{3}$ Physics Department, Bu-Ali Sina University, Hamedan, Iran \\ ${ }^{4}$ Physics Department, Amirkabir University of Technology, Tehran, Iran \\ ${ }^{5}$ Membrane Science and Technology Research Center, Department of Physics, Prince of Songkla University, \\ Songkla, Thailand \\ ${ }^{6}$ Thailand Center of Excellence in Physics, Commission on Higher Education, Bangkok, Thailand \\ ${ }^{7}$ Max-Plank Institute for Polymer Research, Maniz, Germany \\ Email: a pourakbar@iauctb.ac.ir, a.pourakbar@yahoo.com
}

Received 1 May 2014; revised 11 June 2014; accepted 21 July 2014

Copyright (C) 2014 by authors and OALib.

This work is licensed under the Creative Commons Attribution International License (CC BY).

http://creativecommons.org/licenses/by/4.0/

(c) (i) Open Access

\begin{abstract}
Lasers are used to modify the surface morphology, crystallinity, chemical composition, reactivity and resistivity of polymer surfaces. In this work, several cellulose acetate membranes were exposed by ArF excimer laser, $193 \mathrm{~nm}$, at $2-20 \mathrm{UV}$ pulses, with $100-350 \mathrm{~mJ} /$ pulse energy, at $1 \mathrm{~Hz}$ pulse repetition rate. Characterization techniques viz. Fourier transform infra-red spectroscopy (FTIR), Contact angle measurement, Scanning electron microscopy (SEM), Atomic force microscopy (AFM) with roughness analysis, and Water Flux measurement were exploited to understand the induced changes in the surface properties of the polymer. The contact angle measurement was done here, to determine hydrophilicity of the irradiated polymer at various doses. The frequency dependent dielectric behavior was studied both in reference and irradiated samples in the frequency range from $75 \mathrm{KHz}-30 \mathrm{MHz}$. Results showed that the morphological surface changes with laser irradiation, and the water contact angle alters as the surface of the membrane is modified.
\end{abstract}

\section{Keywords}

Cellulose Acetate, Dielectric, Membrane, Excimer Laser, Hydrophilicity

*Corresponding author.

How to cite this paper: Saffar, A.P., Jaleh, B., Parvin, P., Wanichapichart, P. and Farshchi-Tabrizi, M. (2014) Surface Modification and Dielectric Response Investigation of Cellulose Acetate Membrane Treated by ArF Excimer Laser. Open Access Library Journal, 1: e488. http://dx.doi.org/10.4236/oalib.1100488 
Subject Areas: Applied Physics, Atomic Physics, Chemical Engineering \& Technology, Surface and Intersurface of Materials

\section{Introduction}

Polymeric materials for microfiltration membranes cover a wide range, from relatively hydrophilic to very hydrophobic material. Typical hydrophilic materials are polysulfone (PS), poly(ether sulfone) (PES), cellulose (CE) and cellulose acetate (CA), polyamide (PAm), polyimide (PI), and polycarbonate (PC). Typical hydrophobic materials are polyethylene (PE), polypropylene (PP), Teflon (PTFE) and polyvinylidene fluride (PVDF). Hydrophobic membranes do not allow penetration of water into the pore, unless the transmembrane pressure drops, reaching a threshold called the liquid entry pressure of water. The performance of membranes depends on their properties that may be quantified by membrane characterization. The characterization normally concerns with, for example, bulk membrane polymer, membrane surface, pore size and pore distribution. It should be emphasized that the properties of the membrane surface strongly affect membrane performance. Contact angle is often used as a measure of surface hydrophilicity or hydrophobicity. Moreover, X-ray photoelectron spectroscopy (XPS) and Fourier transform infrared spectroscopy (FTIR) provides the data on compositions at the membrane surface. Recently, attentions have been focused on the nodular structure as well as the roughness of the membrane surface that can be measured by atomic force microscopy (AFM) [1]. Development of laser-assisted modification of polymer surfaces is rapidly growing and the method has gained considerable interest among scientists in the past decade. Several experiments and studies have been carried out by using a laser to alter the surface property of materials. Interaction of UV laser pulses with polymers and biological tissues led to a discovery in 1982 of ablative photo decomposition that resulted in the break-up of the structure of organic solid by the photons and the expulsion of the fragments at supersonic velocities [2]. UV laser ablation of polymers can be efficiently done by various excimer lasers such as $\mathrm{XeF}(350 \mathrm{~nm}), \mathrm{XeCl}(308 \mathrm{~nm}), \mathrm{KrF}(248 \mathrm{~nm})$ and $\operatorname{ArF}(193 \mathrm{~nm})$ as well as laser with shortest UV wavelength i.e. molecular fluorine laser (157 nm) [3] [4]. Many studies have also examined the stability of different polymers under UV and IR light, for example [5]-[11]. The polymers investigated included polymethylmethacrylate (PMMA), PVC, polypropylene (PP) and polycarbonate (PC). Interestingly, the UV ablation of polymers by excimer lasers created a difference in stable microstructure on polymer surfaces. The characteristic scale sizes and morphology of the formed structure are dependent on laser wavelength as well as the ablation threshold, the numbers of pulses and kind of polymer [2]. The submicron structure is initiated due to particulate intrinsic impurities in the polymer, which act as masks that shadow the etching process for material underneath [4]. Materials that are irradiated with short high-intensity laser pulses show a number of common features: Significant surface ablation is observed only if the laser fluence F, exceeds a certain threshold fluence $\mathrm{F}_{\mathrm{th}}$. Correspondingly, the experimental observations made with quite different materials can be classified into regimes $\mathrm{F}<\mathrm{F}_{\mathrm{th}}, \mathrm{F}>\mathrm{F}_{\mathrm{th}}$ and $\mathrm{F}>>\mathrm{F}_{\mathrm{th}}$. Pre-ablation $\left(\mathrm{F}<\mathrm{F}_{\mathrm{th}}\right)$, which does not measurably etch the material surface but substantial modification can be permanently induced. Slow ablation $\left(F>F_{t h}\right)$ and etching starts. Fast ablation ( $\mathrm{F}>>\mathrm{F}_{\mathrm{th}}$ ) leading to a constant ablation rate with less surface modification. Etch rates start to increase at fluencies greater than $\mathrm{F}_{\mathrm{th}}$, $\mathrm{UV}$ radiation, like most optical radiations, is absorbed very superficially and the penetration depth in polymer becomes generally fewer than $1 \mathrm{~mm}$. For UVC, it is limited to a few layers of polymeric chains where the spectral region is $100-280 \mathrm{~nm}$ including ArF and $\mathrm{KrF}$ laser lines as well [12].

Laser treatment of materials offers advantages over both chemical and other physical methods. They enable precise modification of certain surfaces that are difficult to treat with conventional chemical methods. The resulting modified surfaces are free from contamination often and, most importantly, the bulk properties of the material remain intact. The UV laser photoablation methods used for the production of miniaturized liquid handling systems on polymer substrate chips. The fabrication of fluid channel and reservoir networks is accomplished by firing $200 \mathrm{~mJ} /$ pulses from a UV excimer laser at substrates moving in predefined computer controlled patterns. This method was used for producing channels in Polystyrene, PC and CA. Relative to original polymer samples, photoablated polymer surfaces showed an increase in their hydrophilcity [13]. In polymers, pulsed $\mathrm{CO}_{2}$ laser inducing surface modification of polyethylene terephthalate (PET) membrane has been investigated and it was found that the morphology and contact angle changed with laser irradiation at various wavelengths and laser 
pulses [14]. The surface of poly ( $\varepsilon$-caprolactone) (PLC) membrane have been modified using excimer laser and Ti:Sapphire femtosecond laser, decreasing the water contact angle of the membrane [15]. The surface properties of collagen and collagen/poly(vinyl pyrrolidone) (PVP) films after KrF excimer laser irradiation $(\lambda=248 \mathrm{~nm})$ were investigated [16]. The method using ArF excimer laser was also successful even in polycarbonate film of $250 \mu \mathrm{m}$ thicknesses, where its morphological changes with the enhanced wetting [17].

In this work, ablation experiments using ArF excimer laser $(193 \mathrm{~nm})$ were carried out to modify the CA membrane surface. Variations of laser parameters such as pulse energy and laser dose were investigated. Characterization techniques using atomic force microscopy, scanning electron microscopy and water contact angle measurements were studied.

\section{Experimental}

\subsection{Materials and Methods}

We have utilized Cellulose Acetate membranes of $47 \mathrm{~mm}$ diameter, $128 \mu \mathrm{m}$ thick and $200 \mathrm{~nm}$ mean pore size, manufactured by (Sartorius) as a target. The excimer laser (Lambda Physik ${ }^{\mathrm{TM}}$, LPX 210) of $193 \mathrm{~nm}, 350$ $\mathrm{mJ} /$ pulse, and $15 \mathrm{~ns}$ pulse duration was used at $1-10 \mathrm{~Hz}$ pulse repetition rate, as the coherent UV source.

\subsection{Membrane Characterization}

The membrane morphology has been studied using an Atomic force microscope (Nanowizard, JPK, Germany) and a scanning electron microscope (Philips SEM model XL30). Scanning electron microscope with secondary electron detector (SE) is used to observe the surface of detector precisely. The polymeric surface usually has no electrical conductance; hence a 10 - $15 \mathrm{~nm}$ gold layer must be provided by sputter coating, to remove electrostatic charge from the surface due to electron beam radiation. In Atomic Force Microscopy (AFM) the topography is mapped out by measuring the mechanical force exerted on the tip due to the tip-surface interaction. AFM has the capability to determine the surface structure of conducting and insulating materials. Both techniques can be used in a vacuum, in air and in liquids. Digital monitoring of surface topography makes it possible to estimate the surface roughness by means of the two parameters: $R_{q}$ (denoted also as RMS) and $R_{a}$ (mean roughness) [18].

Surface hydrophobicity and wettability of membranes were evaluated from contact angle measurements by (Kruss G10) goniometer equipped with image analysis software. The sessile drop method is basically and optical contact angle method, which is the most frequented, used method to estimate wetting properties of a solid surface a droplet of distilled water was deposited on the membrane surface with a precision syringe. The method is based on image processing and curve fitting to contact angle measurement from theoretical meridian drop profile, measuring contact angle between the baseline of drop and the tangent at drop boundary. Video acquisition of a magnified image of drop profiles is conveyed to a computer via a CCD camera, which enables to quantify changes in droplet shape recorded as digital images over time. The contact angles were measured on both sides of the drop and averaged. The FTIR spectra of all samples were recorded in the wave number range of 400 $4000 \mathrm{~cm}^{-1}$ using a Shimadzu FTIR spectrophotometer 8300 .

Precision LCR meter Agilent 4258A with Agilent 16451b Dielectric Test Fixture at various frequencies from $75 \mathrm{kHz}-30 \mathrm{MHz}$ with $1 \mathrm{MHz}$ steps is used to determine the dielectric constant for reference membrane and laser treated ones. The resistivity of the material was calculated using equation $\rho=A /\left(2 \pi f C_{p} D_{t}\right)(\Omega \mathrm{m})$ and dielectric permittivity $\varepsilon=C_{p} / C_{0}$, where $C_{p}$ is the capacitance measured using an LCR meter, $f$ the frequency, $D$ dielectric loss and the $C_{0}$ the vacuum capacitance $=\varepsilon_{0} \mathrm{~A} / t, A$ and $t$ are the cross-sectional area of the electrode and thickness of the sample, respectively. $\varepsilon_{0}$ is the permittivity of vacuum to be equivalent to $8.85 \times 10^{-12}(\mathrm{~F} / \mathrm{m})$ [19].

Experiments were carried out using distilled water as a feed and permeate volume was collected under various applied pressures. The untreated and treated membranes were placed on a support using a dead-end filtering setup. In a preliminary study, water absorption of the membrane was measured. It was found to last $\sim 20$ min before the water content in the membrane reaches to maximal levels. Each one was immersed in distilled water for at least one hour to assure us that any change in flux measurement was quite independent of this water swelling property. According to the Hagenpoissuille equation, the hydraulic permeability coefficient $\left(\mathrm{L}_{\mathrm{p}}\right)$ can be obtained from the slope of the graph between the flux $(\mathrm{J})$ and the applied pressure $(\Delta \mathrm{P})$ according to $\mathrm{J}=\mathrm{L}_{\mathrm{p}} \Delta \mathrm{P}$ [20] [21]. 


\section{Results and Discussion}

Cellulose acetate membranes were chosen for the laser treatment. They were exposed to ArF excimer laser at various UV doses or pulses with the pulse energy of $350 \mathrm{~mJ} /$ pulse, at $1 \mathrm{~Hz}$ pulse repetition rate (Figure 1).

\subsection{SEM and AFM}

Figure 2 and Figure 3 illustrate SEM and AFM micrographs of the untreated CA membranes and laser treated ones at various laser pulses. The UV laser induced effects on the CA surface in terms of laser exposure condition. Untreated membrane (Figure 2(a)) and treated (Figures 2(b)-(e)) show results from the same energy per pulse (same fluence) but differences in pulse numbers. It is obviously seen that the polymer surface undergoes the formation of the microstructure at higher UV doses. Untreated membrane in Figure 3(a) shows similar morphology due to low dose (laser fluence smaller than threshold fluence). Figures 3(b)-(e) show the treated membranes. At high fluences in Figure 3(e), significant changes in surface morphology are observed.

In order to study membrane pore size, scanning electron microscopy was used and SEM micrographs are compared as shown in Figure 2. As is seen, laser pulses $\approx 4\left(0.56 \mathrm{~J} / \mathrm{cm}^{2}\right.$ laser dose $)$ above threshold fluence causes the pores to shrink.

When the pulse numbers increased to $12\left(1.68 \mathrm{~J} / \mathrm{cm}^{2}\right.$ laser dose $)$ and $20\left(2.8 \mathrm{~J} / \mathrm{cm}^{2}\right.$ laser dose), most pores are gradually covered by the melt CA. Table 1 lists roughness analysis $\left(\mathrm{R}_{\mathrm{q}}=\mathrm{RMS}\right.$ roughness, $\mathrm{R}_{\mathrm{a}}=$ Average roughness, $\mathrm{R}_{\mathrm{t}}=$ Peak-to-valley roughness) in $10 \times 10 \mu \mathrm{m}^{2}$ physical size of reference and treated membranes from AFM images.

\subsection{Contact Angle Measurement}

Contact angle was measured as a function of UV laser pulses at $350 \mathrm{~mJ} / \mathrm{pulse}$ and it is plotted, as shown in Figure 4.

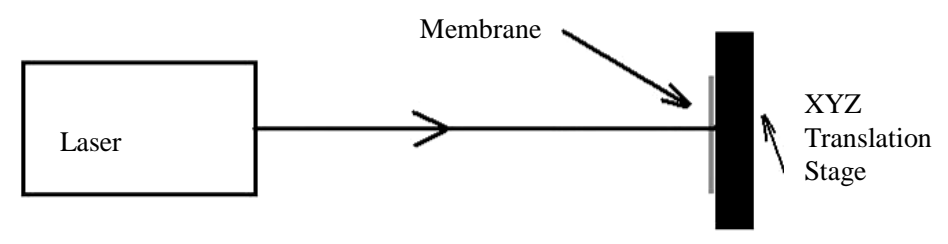

Figure 1. Schematic set up for irradiation on cellulose acetate membrane.
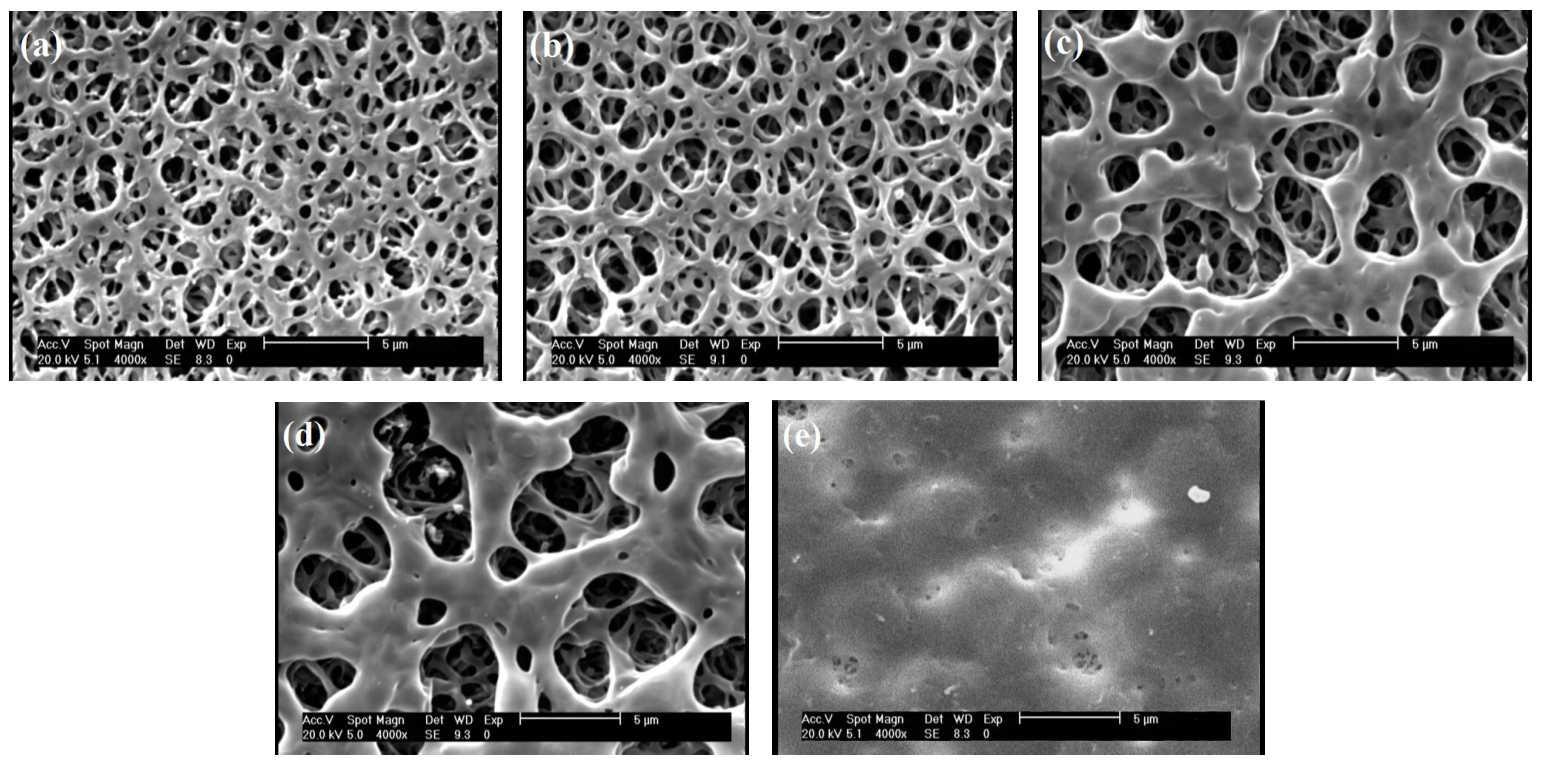

Figure 2. SEM micrographs of membranes (a) the untreated sample, (b) 2 pulses, $0.28 \mathrm{~J} / \mathrm{cm}^{2}$, (c) 4 pulses, $0.56 \mathrm{~J} / \mathrm{cm}^{2}$, (d) 8 Pulses, $1.12 \mathrm{~J} / \mathrm{cm}^{2}$, (e) 20 Pulses, $2.8 \mathrm{~J} / \mathrm{cm}^{2}$. 


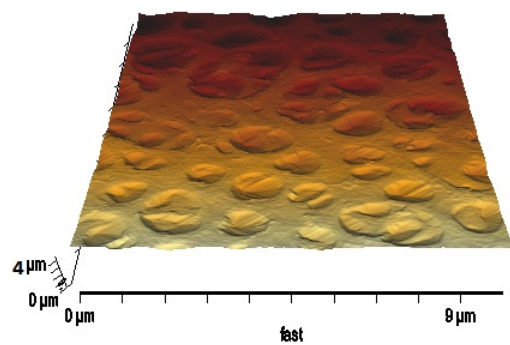

(a)

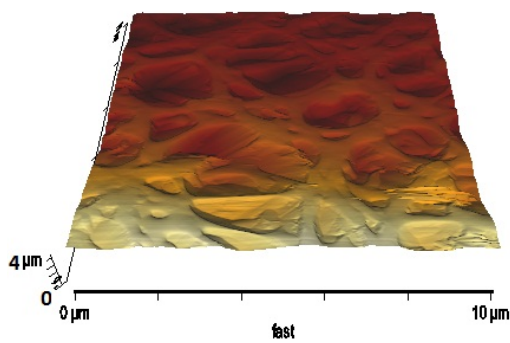

(b)

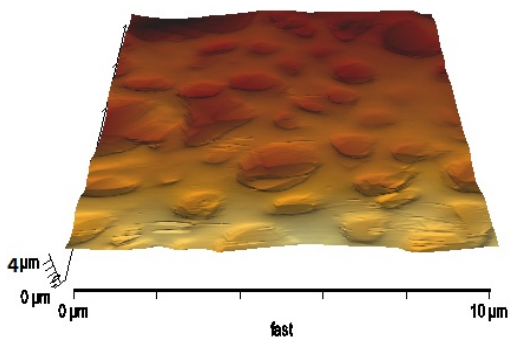

(c)

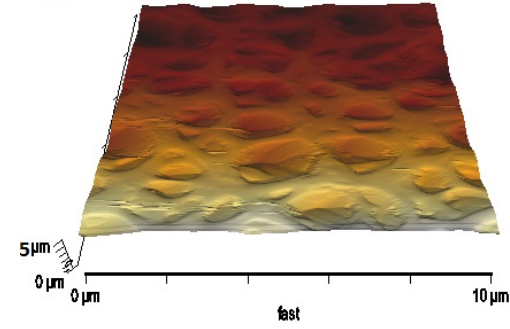

(d)

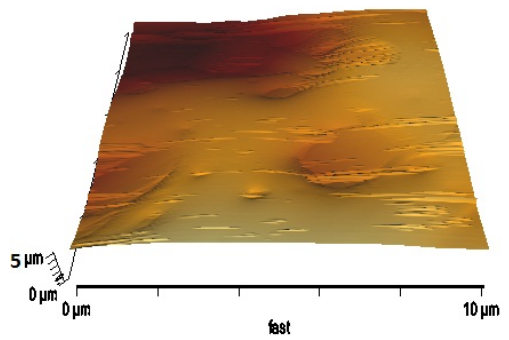

(e)

Figure 3. AFM micrographs of membranes (a) the untreated sample, (b) 4 pulses, $0.56 \mathrm{~J} / \mathrm{cm}^{2}$, (c) 8 pulses, $1.12 \mathrm{~J} / \mathrm{cm}^{2}$, (d) 12 pulses, $1.68 \mathrm{~J} / \mathrm{cm}^{2}$, (e) 20 pulses, $2.8 \mathrm{~J} / \mathrm{cm}^{2}$.

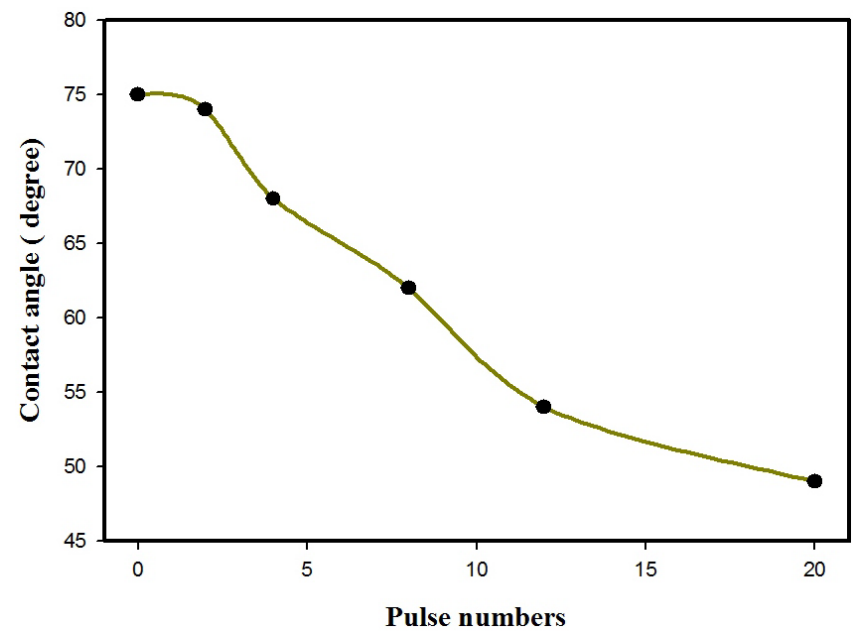

Figure 4. Contact angle measurement as a function of laser pulses.

Table 1. Roughness analysis of cellulose acetate membrane from AFM images.

\begin{tabular}{cccc}
\hline $\begin{array}{c}\text { Number of laser } \\
\text { pulses }\end{array}$ & $\mathrm{R}_{\mathrm{a}}(\mathrm{nm})$ & $\mathrm{R}_{\mathrm{q}}(\mu \mathrm{m})$ & $\mathrm{R}_{\mathrm{t}}(\mu \mathrm{m})$ \\
\hline 0 (Reference) & 866.1 & 1.078 & 4.530 \\
4 & 859.3 & 1.064 & 4.391 \\
8 & 743.8 & 0.935 & 4.848 \\
12 & 981.2 & 1.2 & 5.170 \\
20 & 848.7 & 1.021 & 5.210 \\
\hline
\end{tabular}

The smaller contact angle is corresponding to the greater UV doses. At higher doses, probably changes in surface morphology led to higher hydrophilicity of the membrane. Contact angle for untreated membrane is in agreement with the results reported by (Murtinho et al.) [22]. 


\subsection{FTIR Spectroscopy}

FTIR has often been used as a useful tool in determining specific functional groups or chemical bonds that exist in a material. The presence of a peak at a specific wave number would indicate the presence of a specific chemical bond. In Figure 5, no significant alteration was observed comparing to the untreated membrane and laser treated ones. The vibration of the carbonyl group at $1720 \mathrm{~cm}^{-1}$ is very intense as well as the bands associated with the C-O vibration of the acetyl group $\left(1240 \mathrm{~cm}^{-1}\right)$. Additional vibrations can be assigned to the $-\mathrm{CH}_{3}$ moiety of the acetyl group and two other aliphatic $\left(\mathrm{CH}\right.$ and $\left.\mathrm{CH}_{2}\right)$ groups included in the chain. Most important for us are the decrease of the relative intensity of the $-\mathrm{OH}\left(3470 \mathrm{~cm}^{-1}\right)$ and the increase in the absorbance of the $-\mathrm{CH}_{2}-$ group (2944 and $2885 \mathrm{~cm}^{-1}$ ). The Typical effects of degradation processes, such as chain scission and crosslinking, explain the physical properties of irradiated polymer.

In general, an increase in tensile strength, modulus, hardness and density is interpreted as indicating a predominance of the cross-linking associated with chain scission processes [3]. By increasing laser pulses probably CA membrane surface can be reinforced by cross-linking.

\subsection{Dielectric Response}

Figure 6 shows dielectric constant versus frequency for reference membrane sample and laser treated membranes. After laser treatment CA membrane dielectric constant reduces, it means the pore diameter of membrane increases. AC electrical resistivity versus frequency for untreated Cellulose Acetate and laser treated membrane is shown in Figure 7. It was observed that resistivity decreases with increasing frequency.

The dielectric loss is the power dissipated in a dielectric as heat when the dielectric is exposed to an electric field. Dielectric loss tangent $(\tan \delta)$ is defined as a ratio of energy lost or dissipated per cycle to the energy stored. It was measured directly using an LRC meter/impedance gain phase analyzer. Figure 8 represents the dielectric loss versus frequency for the reference and irradiated samples. It is observed that the dielectric loss increases exponentially with the increasing the frequency.

\subsection{Water Flux Measurement}

In a preliminary study, the membrane could stand a compressive pressure in dead end testing up to $250 \mathrm{kPa}$ without breaking. This is equivalent to a compressive force nearly $380 \mathrm{~N}$. On a permeated volume of distilled water, Figure 9 shows a tendency of relations between the flux and the applied pressure for all membranes. For

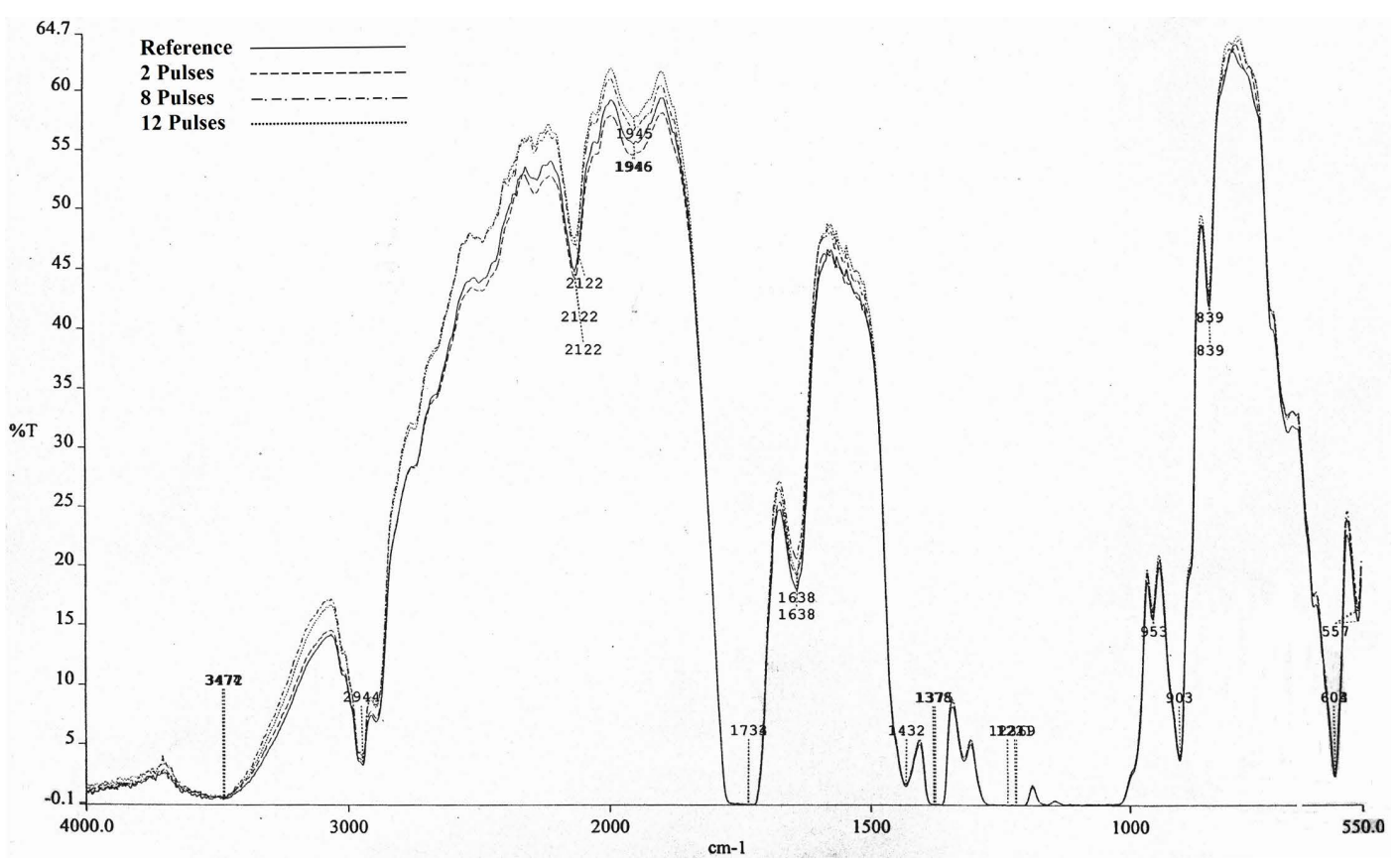

Figure 5. FTIR spectrum of untreated (Reference) and laser treated CA membranes. 


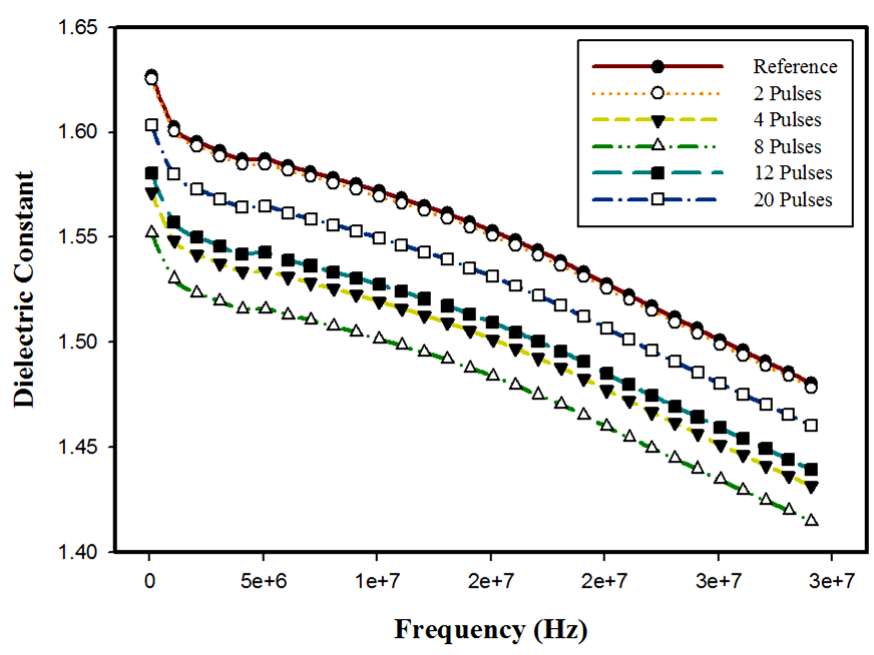

Figure 6. Dielectric constant versus frequency for untreated and treated CA membranes.

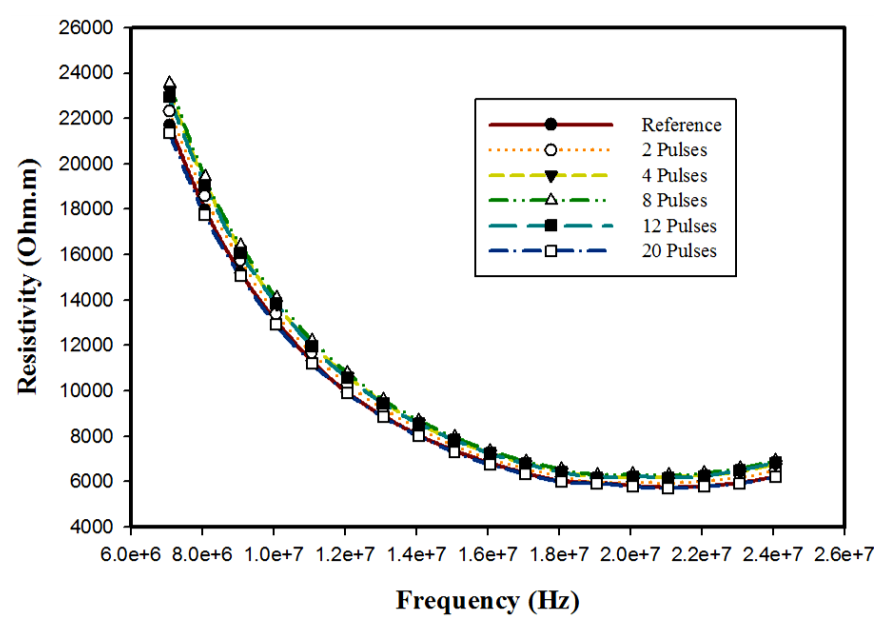

Figure 7. AC electrical resistivity versus frequency for untreated and treated CA membranes.

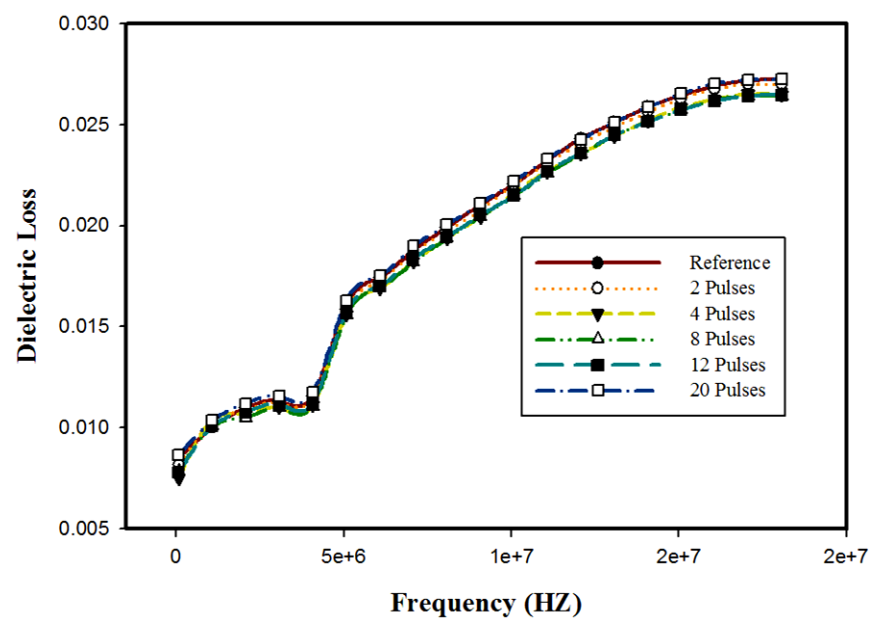

Figure 8. Plot of dielectric loss versus frequency for untreated and treated CA membranes. 


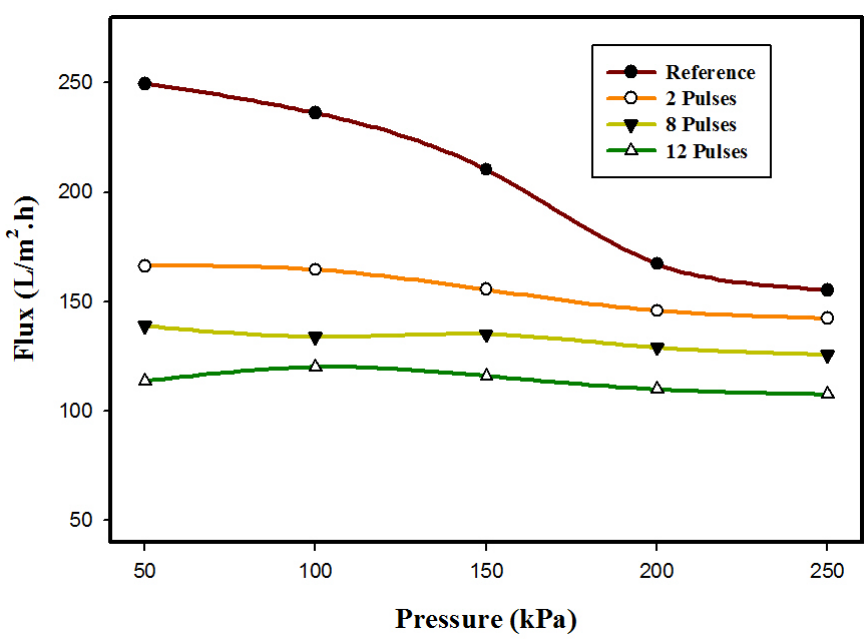

Figure 9. Effect of ArF laser treatment of Cellulose acetate membranes on water fluxes.

high laser doses or pulses, the water flux decreases too. The high value of the water flux and decreases it in reference membrane due to compression of pores under pressure. Polymer cross-linking occurs after laser treatment of membranes, and most pores are gradually covered with the melted cellulose acetate. Hence, water flux of irradiated membranes was decreased compared to the reference one. For treating membranes at higher laser pulses, the water flux decreases too, but no significant changes in water flux were observed with pressure rise. It means no change in compression of the pores has occurred; hence there is a mechanical stability for treating membranes.

\section{Conclusions}

AFM micrographs reveal the formation of the microstructure after UV laser irradiation. On the other hand, results obtained from SEM micrographs show fluence above the threshold value causes shrinkage of membrane pore size and the pores were covered up due to CA melting if the fluence was further increased.

Contact angle measurements have been done to investigate the wettebility changes on CA membrane based on excimer laser treatment. It indicates a hydrophilicity improvement at higher UV doses. Results showed that the morphological surface changes with laser exposure, and the water contact angle decreases as the surface of the membrane is modified. The decrease suggests that hydrophilicity of modified membrane surface by laser irradiation increases in untreated membrane. It indicates that probably skin cross-linking occurs to harden the surface. The growth in $\tan \delta$ and thus decrease in resistivity is brought about by an increase in the conduction of residual current and absorption current.

\section{Acknowledgements}

This work is supported by the Max-Plank Institute for Polymer Research, Mainz-Germany and the National Nanotechnology Center (NANOTEC), NSTDA, Ministry of Science and Technology, Thailand, through its program of Center of Excellence Network.

\section{References}

[1] Khulbe, K.C., Feng, C.Y. and Matsuura, T. (2008) Synthetic Polymeric Membranes. Springer, Berlin.

[2] Srinivasan, R. and Braren, B. (1989) Ultraviolet Laser Ablation of Organic Polymers. Chemical Review, 89, $1303-1308$. http://dx.doi.org/10.1021/cr00096a003

[3] Rabek, J.F. (1996) Photodegradation of Polymer. Springer, Berlin. http://dx.doi.org/10.1007/978-3-642-80090-0

[4] Rubahan, H.G. (1999) Laser Applications in Surface Science and Technology. Wiley, New York.

[5] Zhang, Z., Hu, X. and Luo, Z. (1996) Wavelength Sensitivity of Photo-Oxidation of Polypropylene. Polymer Degradation and Stability, 51, 93-97. http://dx.doi.org/10.1016/0141-3910(95)00210-3 
[6] Torikai, A. and Hasegawa, H. (1998) Wavelength Effect on the Accelerated Photodegradation of Polymethylmethacrylate. Polymer Degradation and Stability, 61, 361-364. http://dx.doi.org/10.1016/S0141-3910(97)00119-5

[7] Gesenhues, U. (2000) Influence of Titanium Dioxide Pigments on the Photodegradation of Poly(Vinyl Chloride). Polymer Degradation and Stability, 68, 185-196. http://dx.doi.org/10.1016/S0141-3910(99)00184-6

[8] Geretovsky, Z., Hopp, B., Bertoti, I. and Boyd, I.W. (2002) Photodegradation of Polycarbonate under Narrow Band Irradiation at $172 \mathrm{~nm}$. Applied Surface Science, 186, 85-90. http://dx.doi.org/10.1016/S0169-4332(01)00615-8

[9] Lippert, T. and Thomas Dickinson, J. (2003) Chemical and Spectroscopic Aspects of Polymer Ablation: Special Features and Novel Directions. Chemical Review, 103, 453-485. http://dx.doi.org/10.1021/cr010460q

[10] Panchenko, A.N., Shulepov, M.A., Tel’minov, A.E., Zakharov, L.A., Paletsky, A.A. and Bulgakova, N.M. (2011) Pulsed IR Laser Ablation of Organic Polymers in Air: Shielding Effects and Plasma Pipe Formation. Journal of Physics D: Applied Physics, 44, Article ID: 385201. http://dx.doi.org/10.1088/0022-3727/44/38/385201

[11] Sang, W.W. and Seung, M.P. (2001) Laser Ablation of Poly(Methyl Methacrylate) at $266 \mathrm{~nm}$. Bulletin of the Korean Chemical Society, 22, 914-916.

[12] Jaleh, B., Parvin, P., Katoozi, M., Zamani, Z. and Zare, A. (2005) Etching Microscopic Defects in Polycarbonate Due to High Dose ArF or KrF Laser Exposure. Radiation Measurements, 40, 770-774. http://dx.doi.org/10.1016/j.radmeas.2005.06.035

[13] Roberts, M.A., Rossier, J.S., Bercier, P. and Girault, H. (1997) UV Laser Machined Polymer Substrates for the Developmentvof Micro-Diagnostic Systems. Analytical Chemistry, 69, 2035-2042. http://dx.doi.org/10.1021/ac961038q

[14] Dadsetan, M., Mirzadeh, H. and Sharifi, N. (1999) Effect of $\mathrm{CO}_{2}$ Laser Irradiation on Surface Properties of Polyethylene Terephthalate. Radiation Physics and Chemistry, 56, 597-604. http://dx.doi.org/10.1016/S0969-806X(99)00293-5

[15] Tiaw, K.S., Goh, S.W., Hong, M., Wang, Z., Lan, B. and Teoh, S.H. (2005) Laser Surface Modification of Poly(ع-caprolactone) (PLC) Membrane for Tissue Engineering Applications. Biomaterials, 26, 763-769. http://dx.doi.org/10.1016/j.biomaterials.2004.03.010

[16] Wisniewski, M., Sionkowska, A., Kaczmarek, H., Skopinska, J., Lazare, S. and Tokarev, V. (2006) The Influence of $\mathrm{KrF}$ Excimer Laser Irradiation on the Surface of Collagen and Collagen/PVP Films. International Journal of Photoenergy, 2006, Article ID: 35126. http://dx.doi.org/10.1155/IJP/2006/35126

[17] Jaleh, B., Parvin, P., Sheikh, N., Zamanipour, Z. and Sajad, B. (2007) Hdrophilicity and Morphological Investigation of Polycarbonate Irradiated by ArF Excimer Laser. Nuclear Instruments and Methodes B, 265, 330-333. http://dx.doi.org/10.1016/j.nimb.2007.08.067

[18] Kowal, A. (2005) Application of STM and AFM Techniques for the Investigation of Corrosion Processes and Materials Protection. Zaštita Materijala (Materials Protection), 46.

[19] Shah, S., Qureshi, A., Singh, N.L., Singh, K.P. and Avasthi, D.K. (2008) Dielectric Response of Proton Irradiated Polymer Composite Films. Radiation Measurements, 43, S603-S606. http://dx.doi.org/10.1016/j.radmeas.2008.04.038

[20] Wanichapichart, P., Taweepreeda, W., Choomgan, P. and Yu, L.D. (2010) Argon and Nitrogen Beams Influencing Membrane Permeate Fluxes and Microbial Growth. Radiation Physics and Chemistry, 79, 214-218. http://dx.doi.org/10.1016/j.radphyschem.2009.08.040

[21] Jaleh, B., Parvin, P., Wanichapichart, P., Pourakbar Saffar, A. and Reyhani, A. (2010) Induced Super Hydrophilicity Due to Surface Modification of Polypropylene Membrane Treated by $\mathrm{O}_{2}$ Plasma. Applied Surface Science, 257, 16551659. http://dx.doi.org/10.1016/j.apsusc.2010.08.117

[22] Murtinho, D., Lagoa, A.B., Garcia, F.A.P. and Gil, M.H. (1998) Cellulose Derivatives Membranes as Supports for Immobilization of Enzymes. Cellulose, 5, 299-308. http://dx.doi.org/10.1023/A:1009255126274 